\title{
Glial Fibrillary Acidic Protein (GFAP): Neuroinflammation Biomarker in Acute Ischemic Stroke
}

\section{Lisda Amalia (1D}

Department of Neurology, The First Affiliated Hospital of Faculty of Medicine, Universitas Padjadjaran/RSUP dr. Hasan Sadikin, Bandung, Indonesia
Correspondence: Lisda Amalia Jl.Pasteur 38, Bandung, 40161, Indonesia Email dr.lisda@gmail.com
Introduction: Blockage of the cerebral arteries due to thrombosis and embolism resulting in decreased blood flow to the brain, reduced oxygen supply to the brain, resulting in neuronal damage and causes astrocyte cells to secrete glial fibrillary acidic protein (GFAP). The objective of this study was to determine the correlation between GFAP levels serum and clinical outcome in patients with acute ischemic stroke.

Methods: This was observational with a cross-sectional design on acute ischemic stroke patients confirmed by CT scans and divided into large vessel occlusion and small-vessel occlusion. Clinical outcome was measured using the National Institutional Health Stroke Scale (NIHSS) tool. Statistical analysis uses Spearman's rank correlation test and Mann Whitney's test, significant if $\mathrm{p}<0.05$.

Results: After collecting 33 research subjects, we found 16 people with large vessel occlusion and 17 people with small vessel occlusion. Serum GFAP levels were $0.2-1.9 \mathrm{ng} /$ $\mathrm{mL}, 9.1 \%$ with a mild neurological deficit, $45.45 \%$ were moderate neurological deficits, and $45.45 \%$ were severe neurological deficits. There was a significant positive correlation $(\mathrm{r}=$ $0.522 ; \mathrm{p}=0.002$ ) between serum GFAP levels and the degree of neurological deficit in ischemic stroke patients. There was a statistically significant difference between serum GFAP levels in ischemic stroke patients with CT scan results of large artery occlusion compared to small artery occlusion $(0.7$ vs $0.4 \mathrm{ng} / \mathrm{mL} ; \mathrm{p}=0.001)$.

Conclusion: There was a positive correlation between GFAP level serum and NIHSS score on acute ischemic stroke. The higher the value of GFAP serum level, the higher the value for NIHSS and correlated with stroke severity and the extent of brain damage in ischemic stroke patients.

Keywords: GFAP, clinical outcome, acute ischemic stroke, small vessel occlusion, large vessel occlusion

\section{Introduction}

Stroke is a neurological emergency that arises suddenly and is the 3rd cause of death in the world after heart disease and cancer. ${ }^{1}$ Ischemic stroke is the most common type of stroke, accounting for $87 \%$ of all strokes worldwide. Impaired blood-brain barrier permeability causes GFAP to diffuse into the cerebrospinal fluid and then enter the blood circulation to detect GFAP levels in the blood. GFAP levels can begin to be detected in the blood after 12 hours of the onset of ischemic stroke and reach the highest levels after 48 hours of the onset of ischemic stroke. ${ }^{2,3}$

There is hyperreactivity of astrocytes as a result of glutamate excitotoxicity, which can cause changes in astrocytes, namely astrocytes experience hypertrophy 
and proliferation which is referred to as the astrogliosis process in acute ischemic stroke. Prolonged astrogliosis in patients with brain ischemia can increase neuronal death and exacerbate brain tissue degeneration. This astrogliosis process is characterized by a rapid and high increase in GFAP levels because damaged astrocytes secrete GFAP. Astrocytes are cells that make up the blood-brain barrier, so if there is damage to the blood-brain barrier, it will cause GFAP levels to increase and enter the bloodstream. ${ }^{4}$

GFAP level serum can be used to assess neurologic deficits, monitor therapy, and prognosticate ischemic stroke. In ischemic stroke, the greater the damage to neurons and neuroglia, the serum GFAP levels will increase, and there is a relationship between high GFAP levels and the severity of the neurological deficit and the extent of brain damage in ischemic stroke patients. The larger the infarct area, the higher the serum GFAP level and NIHSS score. ${ }^{3}$

Based on the above framework, this study aims to determine the correlation between serum GFAP levels and clinical outcomes based on the NIHSS score in ischemic stroke patients.

\section{Methods}

It was an observational correlative analysis with a crosssectional design at RSUP. Dr. Hasan Sadikin from June 2015 to November 2015.

\section{Clinical and Imaging Evaluation}

The research subjects were patients diagnosed with ischemic stroke confirmed by CT scan who came to the hospital within five days after stroke onset and were grouped into large vessel occlusion and small-vessel occlusion based on clinical symptoms and imaging. We exclude the presence of a history of previous stroke, head trauma, patients with glioblastoma multiforme. The results of the NIHSS criteria assessment are scores, namely a score of $<4$ indicating a mild neurological deficit, a score of 5-12 indicating a moderate neurological deficit, and a score of $>12$ indicating a severe neurological deficit.

\section{GFAP Measurement}

Examination of serum GFAP levels was on admission using Enzyme Link Immunosorbent Assay (ELISA). Storage of serum examination material at a temperature of $28^{\circ} \mathrm{C}$ can be stable for up to 5 days at a temperature of $-20^{\circ} \mathrm{C}$; it is stable for one month, and at a temperature of $-80^{\circ} \mathrm{C}$ it is stable for six months. Before examining serum GFAP levels, the instrument will calibrate and the serum centrifuge at
$3000 \mathrm{rpm}$ for 20 minutes. The serum formed was separated and put into a microtube and then stored at $-80^{\circ} \mathrm{C}$ until a predetermined number of samples was obtained.

\section{Statistics}

We use IBM SPSS 22.0 (IBM Corp, Armonk, NY) for statistical analysis. This study uses the Spearman rank-test and Mann-Whitney's test. $\mathrm{p}$ value below 0.05 is considered significant, and the $r$ coefficient was calculated to establish the correlation.

\section{Ethical Approval}

Dr. Hasan Sadikin General Hospital Bandung Human Research Ethics Committee (LB.04.01/A05/EC/222/VI/ 2015) had approved this study. This study had complied with all relevant ethical regulations (including The Declaration of Helsinki). All patients were informed about the purpose of the study and had obtained written consent.

\section{Results}

Table 1 shows that the mean age of the study subjects was 57.14 years, most of which consisted of men (60.61\%) from 33 study subjects. In this study, the minimum value for serum GFAP levels was $0.2 \mathrm{ng} / \mathrm{mL}$, and the maximum value was $1.9 \mathrm{ng} / \mathrm{mL}$ (reference value in ordinary people is $<0.0018 \mathrm{ng} / \mathrm{mL}$ ). We found 3 study subjects $(9.1 \%)$ in mild neurological deficit, a moderate degree of neurological deficit in 15 study subjects $(45.45 \%)$, and severe neurological deficit degree in 15 study subjects $(45.45 \%)$. The number of research subjects with hypertension was 29 subjects (87.87\%), dyslipidemia was 16 subjects (48.48\%), diabetes mellitus was eight subjects (24.25\%), and smokers were 16 subjects (48.48\%).

Statistical analysis results between serum GFAP levels and the degree of neurological deficit based on the NIHSS score using the Spearman correlation test (rs) obtained a significant positive correlation with a moderate correlation strength of 0.522 (95\% confidence level). Table 2 shows the correlation between serum GFAP levels and the degree of neurologic deficit based on NIHSS scores. Increasing GFAP level serum will increase the NIHSS score, which indicates a more severe neurological deficit, and a decrease will follow vise versa in lower serum GFAP levels which indicate a milder neurological deficit.

Table 3 shows the difference between serum GFAP levels in ischemic stroke patients with $\mathrm{CT}$ scan results of large artery occlusion and small artery occlusion. It 
Table I Clinical Characteristic of Research Subjects

\begin{tabular}{|c|c|c|c|}
\hline Characteristic & Mean \pm SD & Min-Max & n (\%) \\
\hline Age (years old) & $57.14 \pm 18.27$ & & \\
\hline \multicolumn{4}{|l|}{ Gender } \\
\hline Male & & & $20(60.6)$ \\
\hline Female & & & $13(39.4)$ \\
\hline GFAP serum $(\mathrm{ng} / \mathrm{mL})$ & & $0.2-1.9$ & \\
\hline NIHSS score & & $4-21$ & \\
\hline Mild neurological deficit $(<5)$ & & & $3(9.2)$ \\
\hline Moderate neurological deficit & & & $15(45.4)$ \\
\hline \multicolumn{4}{|l|}{$(5-14)$} \\
\hline Severe neurological deficit & & & $15(45.4)$ \\
\hline \multicolumn{4}{|l|}{$(\geq 15)$} \\
\hline \multicolumn{4}{|l|}{ Risk factors } \\
\hline \multicolumn{4}{|l|}{ Hypertension } \\
\hline Yes & & & $29(87.9)$ \\
\hline No & & & $4(12.1)$ \\
\hline \multicolumn{4}{|l|}{ Dyslipidemia } \\
\hline Yes & & & $16(48.5)$ \\
\hline No & & & $17(5 \mid .5)$ \\
\hline \multicolumn{4}{|l|}{ Diabetes melitus } \\
\hline Yes & & & $8(24.3)$ \\
\hline No & & & $25(75.7)$ \\
\hline \multicolumn{4}{|l|}{ Smoking } \\
\hline Yes & & & $16(48.5)$ \\
\hline No & & & $17(5 \mid .5)$ \\
\hline
\end{tabular}

Abbreviations: SD, standard deviation; min-max, minimum-maximum.

shows the tendency that serum GFAP levels are increasing in ischemic stroke patients who have CT scan results with large artery occlusion. Results of statistical tests using the Mann-Whitney Test at a 95\% confidence level showed that there was a statistically significant difference between serum GFAP levels of ischemic stroke patients and CT scan results of large artery occlusion

Table 2 Correlation Between GFAP Level Serum and NIHSS

\begin{tabular}{|l|c|c|}
\hline Correlation Research Variable & $\mathbf{r}_{\mathbf{s}}$ & $\mathbf{p}$ value \\
\hline Correlation GFAP level serum and NIHSS score & 0.522 & 0.002 \\
\hline
\end{tabular}

Note: Significant if $p<0.05$.

Abbreviation: $r_{\mathrm{s}}$, Spearman correlation test. compared to small artery occlusion $(0.7$ vs $0.4 \mathrm{ng} / \mathrm{mL}$; $\mathrm{p}=0.001)$.

\section{Discussion}

The subjects analyzed in this study amounted to 33 people with a mean age of 57.14 years. Elderly is one of the nonmodifiable risk factors for ischemic stroke. Older adults tended to stroke. Based on the American Heart Association (AHA), the risk of stroke doubles every ten years of 55 years. The mean age of the subjects in this study was 57.14 years, which is by previous studies. This study found that the mean age of stroke patients was 58.8 years. Basic Health Research in 2013 also found that the average age of stroke patients was 59 years. $^{5,6}$

Table 3 Difference Between GFAP Level Serum in Large Artery Occlusion and Small Artery Occlusion Group

\begin{tabular}{|l|c|c|c|}
\hline \multirow{2}{*}{} & \multicolumn{2}{|c|}{ GFAP Level $(\mathrm{ng} / \mathrm{mL})$} & P value* \\
\cline { 2 - 4 } & Median & Minimum-Maximum & \\
\hline CT scan & & & 0.001 \\
Large artery occlusion $(n=16)$ & 0.7 & $0.5-1.9$ & \\
Small artery occlusion $(n=17)$ & 0.4 & $0.2-1.0$ & \\
\hline
\end{tabular}

Note: *Mann Whitney Test $(\mathrm{p}<0.05)$. 
In this study, male subjects were more $(60.61 \%)$ than women $(39.39 \%)$. These results follow statistical data from the American Heart Association (AHA) in 2015, which found that the number of men with ischemic stroke was more than women in the 45-59 year age group. The incidence of stroke in women who do not have menopause is lower because of the influence of the hormone estrogen, which functions to provide protection and prevent the process of atherosclerosis of blood vessels. ${ }^{6}$

This study found that hypertension was the most common stroke risk factor in research subjects (87.87\%). According to the AHA in 2015, $40 \%$ of ischemic stroke patients in the 45-64 year group have hypertension. The incidence of hypertension in patients with ischemic stroke in America is lower due to hypertension patients receiving regular treatment, thereby reducing the risk of ischemic stroke in the $40-59$ year age group. ${ }^{6}$

Statistical analysis results regarding the correlation between serum GFAP levels and the degree of neurological deficit based on the NIHSS score in ischemic stroke patients in this study (data available in Supplementary material) obtained a significant positive correlation with moderate correlation strength $(r s=0.522 ; \mathrm{p}=0.002)$. The results of previous studies also found a positive correlation with moderate strength between serum GFAP levels and the degree of neurological deficit based on the NIHSS score in ischemic stroke patients $(r s=0.486 ; \mathrm{p}=0.0001)$. It shows that increasing GFAP levels are associated with the severity of the neurological deficit that occurs, or in other words, a high serum GFAP level associates with an increasingly severe NIHSS score. It is appropriate that high serum GFAP levels can be a marker of poor neurological outcomes in ischemic stroke patients. $^{3}$

Biological markers in ischemic stroke that can determine brain damage at the onset of brain ischemia are IL-10, IL-6, $\mathrm{TNF} \alpha$, intercellular adhesion molecule-1, vascular cell adhesion molecule-1, and soluble CD40 ligand as markers of inflammation; glutamate (Glu) and aspartate as markers of the occurrence of excitotoxicity processes in stroke; neuronspecific enolase (NSE) as a marker of neuronal damage; protein S100B and glial fibrillary acidic protein (GFAP) as markers of glial cell damage; and matrix metalloproteinase-9 (MMP-9) and cellular fibronectin as markers of blood-brain barrier damage. Glial Fibrillary Acidic Protein (GFAP) is a marker that can help establish the diagnosis of ischemic stroke and hemorrhagic stroke and for stroke prognosis., ${ }^{7,8}$

Glial Fibrillary Acidic Protein (GFAP) is a cytoskeletal protein, the main filament in mature astrocytes in the central nervous system (CNS), with a filament length of 8-9 $\mathrm{nm}$. The GFAP protein gene locates on the long arm of chromosome 17q21. GFAP expresses as a non-soluble monomeric protein consisting of 432 amino acids with a 49.8-53 kiloDalton $(\mathrm{kDa})$ molecular weight in normal astrocytes. GFAP is produced only by astrocytes, so this protein is found explicitly in the brain. ${ }^{9}$

Astrogliosis is a molecular, cellular, and functional change in astrocytes that responds to injury to the central nervous system. Astrocytes are the first cells to maintain hemostasis and respond when an ischemic process occurs in the brain. Condition in which the brain or part of the brain does not get enough oxygen and nutrients, resulting in brain cell dysfunction and death. Reduced cerebral blood flow in cerebral ischemia can cause impaired astrocyte ion pump function and disrupt homeostasis, characterized by an increase in intracellular $\mathrm{Ca} 2+$ and extracellular $\mathrm{K}+$. Astrocytes hypertrophy and proliferate several hours after brain injury due to structural displacement and macrophages in ischemic areas. Activated astrocytes secrete a large number of molecules that benefit ischemic nerve cells by regulating various biological processes. Ischemic conditions can trigger astrogliosis. Astrocyte activation occurs in all cases of CNS damage, regardless of the brain region involved or the type of brain cell damaged. ${ }^{8}$ Astrogliosis plays a role in repair immediately after brain injury; an example of the trophic function of activated astrocytes is an increase in neurotrophic factors, such as glial cell-derived neurotrophic factors (GDNF). ${ }^{9}$ In GFAP-GDNF transgenic mice, there was an increase in GDNF in astrocytes and the number of specific motor neurons by reducing brain cell death during ischemia. Astrocytes also play an essential role in regulating extracellular glutamate by limiting the excitotoxicity of glutamate to neurons and other brain cells so that if excessive astrocytes are reactive, they can exacerbate brain nerve cell damage. Excessive reactive astrocytes after CNS injury in mice can increase neuronal death and exacerbate brain tissue degeneration. ${ }^{10-12}$ Astrogliosis is an increase in intermediate filaments accompanied by hypertrophy and an increase in the number of astrocytes. Reactive astrogliosis will increase the expression of Glial Fibrillary Acidic Protein (GFAP) and the release of several pro-inflammatory cytokines, namely tumor necrosis factor (TNF), interleukin (IL), interferon (IFN), and matrix metalloproteinase (MMP). Glial Fibrillary Acidic Protein is the essential intermediate filament in mature astrocytes and plays an essential role in the integrity of the astrocyte cytoskeleton. Reactive astrocytes also produce urokinase plasminogen activator (u-PA) and tissue 
plasminogen activator (tPA), which aid in forming plasmin from plasminogen. Increased calcium in the cell cytoplasm activates the neural enzyme nitric oxide synthase (nNOS), thereby increasing the production of nitric oxide (NO), which causes oxidative stress. The binding nuclear factor-kappa $\mathrm{B}$ (NF-kB) to the DNA promoter site cause reactive astrogliosis. ${ }^{20}$ Excessive reactive astrocytes can produce proinflammatory and cytotoxic cytokines that are harmful to neurons or oligodendrocytes in the injured brain, which in turn can cause more severe brain damage. ${ }^{7}$ Increasing GFAP levels during astrogliosis has been shown in several studies. GFAP is a sensitive marker of astrogliosis and increases immediately after CNS injury. ${ }^{13}$ The role of reactive astrogliosis in the development of cerebral ischemic lesions is not known for sure, but this study shows that neurons and the occurrence of astrocyte malfunction in ischemic processes can cause neuronal degeneration. ${ }^{14}$ Disruption of astrocytes in stroke is associated with loss of the body's defense function to increase the expansion of the inflammatory process and infarct volume. ${ }^{15}$

Prolonged astrogliosis can be dangerous because it can limit the regeneration of axons, thereby slowing the functional repair of the brain and secreting large amounts of neurotoxic compounds, which can give a poor prognosis in ischemic stroke. ${ }^{16}$ Prolonged astrocyte activation will adversely affect axon growth. Hypertrophied astrocytes will cause the accumulation of extracellular matrix at the site of injury, which consists mainly of chondroitin sulfate proteoglycans. ${ }^{17}$ The buildup of the extracellular matrix causes the formation of dense structures that can inhibit axon regeneration and form scar tissue. There was an increase in axon regeneration in GFAP and vimentindeficient mice so that if the astrogliosis process was limited, it could improve axon regeneration after nerve injury. $^{14}$

Elevated levels of GFAP in ischemic stroke are found in cerebrospinal fluid and serum. ${ }^{3,4}$ The GFAP polymer will disintegrate to form soluble fragments with a molecular weight of $41 \mathrm{kDa}$ released into the surrounding interstitial fluid. ${ }^{16}$ GFAP enters the bloodstream from the cerebrospinal fluid by increasing the difference in cerebrospinal fluid and blood concentrations. Damage to the blood-brain barrier in ischemic stroke due to brain tissue death occurs slowly, whereas, in hemorrhagic stroke, the blood-brain barrier damage rapidly so that large amounts of GFAP will enter the circulation. ${ }^{2,18,19}$ Several studies have shown that GFAP levels can be used as a biological marker to help establish the diagnosis and prognosis of ischemic stroke. Glial Fibrillary Acidic Protein levels can find in CSF, serum, and plasma. GFAP levels in the serum of ischemic stroke patients increase within 8 hours after stroke onset and reach maximum levels between days 2 and 5. ${ }^{19}$ GFAP levels can detect in serum within a few hours after the onset of hemorrhagic stroke, but in ischemic stroke, GFAP levels are detectable in serum for a longer time. In a hemorrhagic stroke, there is a sudden breakdown of the blood-brain barrier with early brain damage. The structural integrity of brain cells and the brain barrier can last longer, so that brain cell death due to necrotic and lysis only appears 6-12 hours after the blockage of the blood vessels in ischemic stroke. GFAP levels in ischemic stroke reach their peak after 4872 hours after onset. ${ }^{4}$ Accordingly, the combination of D-dimer and GFAP with stroke scale may provide a simple and highly accurate tool for identifying large vessel occlusion. $^{21}$

Statistical analysis tests using the Mann Whitney Test at a 95\% confidence level showed that there was a statistically significant difference between serum GFAP levels of ischemic stroke patients and CT scan results of large artery occlusion compared to small artery occlusion ( 0.7 vs $0.4 \mathrm{ng} / \mathrm{mL} ; \mathrm{p}=0.001)$. Patients with ischemic stroke found the mean value of GFAP levels began to increase 6 hours after stroke onset and reached peak values at 48 hours after onset. GFAP levels are strongly correlated with the severity of neurological deficits as measured by the NIHSS score and infarct volume so that GFAP levels can also use as a prognostic marker in ischemic stroke patients. GFAP levels are also associated with the outcome of ischemic stroke patients after three months of stroke. $^{3,4,22}$

\section{Conclusion}

There was a positive correlation between GFAP-level serum and NIHSS score on acute ischemic stroke. The higher the value of GFAP serum level, the higher the value for NIHSS and correlated with stroke severity and the extent of brain damage in ischemic stroke patients.

\section{Disclosure}

The author reports no conflicts of interest in this work.

\section{References}

1. Saenger AK, Christenson RH. Stroke biomarkers: progress and challenges for diagnosis, prognosis, differentiation, and treatment. Clin Chem. 2009;56(1):21-33. doi:10.1373/clinchem.2009.133801 
2. Foerch C, Niessner M, Back T, et al. Diagnostic accuracy of plasma glial fibrillary acidic protein for differentiating intracerebral hemorrhage and cerebral ischemia in patients with symptoms of acute stroke. Clin Chem. 2012;58(1):237-245. doi:10.1373/clinchem. 2011.172676

3. Wunderlich MT, Wallesch CW, Goertler M. Release of glial fibrillary acidic protein is related to the neurovascular status in acute ischemic stroke. Eur J Neurol. 2006;13(10):1118-1123. doi:10.1111/j.14681331.2006.01435.x

4. Dvorak F, Haberer I, Sitzer M, Foerch C. Characterisation of the diagnostic window of serum glial fibrillary acidic protein for the differentiation of intracerebral haemorrhage and ischaemic stroke. Cerebrovasc Dis. 2009;27(1):37-41. doi:10.1159/000172632

5. Badan Penelitian dan Pengembangan Kesehatan Kementerian Kesehatan. Laporan Hasil Riset Kesehatan Dasar. Jakarta; 2013. Available from: www.litbang.depkes.go.id/resources/download/ materi_pertemuan/launch_riskesdas/Riskesdas\%20Launchingpdf. Accessed December 12, 2021.

6. Mozaffarian D, Benjamin EJ, Go AS, et al. Heart disease and stroke statistics-2015 update: a report from the American Heart Association. Circulation. 2015;131(4):e29-e322. doi:10.1161/ CIR.0000000000000152

7. Oleszak EL, Zaczynska E, Bhattacharjee M, Butunoi C, Legido A, Katsetos CD. Inducible nitric oxide synthase and nitrotyrosine are found in monocytes/macrophages and/or astrocytes in acute, but not in chronic, multiple sclerosis. Clin Diagn Lab Immun. 1998;5 (4):438-445. doi:10.1128/CDLI.5.4.438-445.1998

8. Wakasa S, Shiiya N, Tachibana T, Ooka T, Matsui Y. A semiquantitative analysis of reactive astrogliosis demonstrates its correlation with the number of intact motor neurons after transient spinal cord ischemia. J Thorac Cardiovasc Surg. 2009;137 (4):983-990. doi:10.1016/j.jtcvs.2008.10.002

9. Norenberg MD, Rao KVR, Jayakumar AR. Mechanisms of ammonia-induced astrocyte swelling. Metab Brain Dis. 2005;20 (4):303-318. doi:10.1007/s11011-005-7911-7

10. Oppenheim RW, Houenou LJ, Parsadanian AS, Prevette D, Snider WD, Shen L. Glial cell line-derived neurotrophic factor and developing mammalian motoneurons: regulation of programmed cell death among motoneuron subtypes. $J$ Neurosci. 2000;20 (13):5001-5011. doi:10.1523/JNEUROSCI.20-13-05001.2000
11. Struzynska L. A glutamatergic component of lead toxicity in adult brain: the role of astrocytic glutamate transporters. Neurochem Int. 2009;55(1-3):151-156. doi:10.1016/j.neuint.2009.01.025

12. Myer DJ, Gurkoff GG, Lee SM, Hovda DA, Sofroniew MV. Essential protective roles of reactive astrocytes in traumatic brain injury. Brain. 2006;129(Pt 10):2761-2772. doi:10.1093/brain/awl165

13. Chen Y, Swanson RA. Astrocytes and brain injury. J Cereb Blood Flow Metab. 2003;23(2):137-149. doi:10.1097/01. WCB.0000044631.80210.3C

14. Li L, Lundkvist A, Andersson D, et al. Protective role of reactive astrocytes in brain ischemia. $J$ Cereb Blood Flow Metab. 2008;28 (3):468-481. doi:10.1038/sj.jcbfm.9600546

15. Petzold A. Glial fibrillary acidic protein is a body fluid biomarker for glial pathology in human disease. Brain Res. 2015;1600:17-31. doi:10.1016/j.brainres.2014.12.027

16. Petzold A, Keir G, Green AJ, Giovannoni G, Thompson EJ. An ELISA for glial fibrillary acidic protein. $J$ Immunol Methods. 2004;287(1-2):169-177. doi:10.1016/j.jim.2004.01.015

17. Abadier MZ, Eliwa GH, Mohamed -MA-M, Ahmed ZM, AbdelSalam OA. Plasma glial fibrillary acidic protein, D-Dimer and S100 $\beta$ protein: a panel for differential diagnosis of acute stroke. $J$ Am Sci. 2012;8(5):267-272.

18. Araque A, Carmignoto G, Haydon PG. Dynamic signaling between astrocytes and neurons. Annu Rev Physiol. 2001;63:795-813. doi:10.1146/annurev.physiol.63.1.795

19. Herrmann M, Vos P, Wunderlich MT, de Bruijn CHMM, Lamers KJB. Release of glial tissue-specific proteins after acute stroke: a comparative analysis of serum concentrations of protein S-100B and glial fibrillary acidic protein. Stroke. 2000;31 (11):2670-2677. doi:10.1161/01.STR.31.11.2670

20. Pekny M, Pekna M. Astrocyte reactivity and reactive astrogliosis: costs and benefits. Physiol Rev. 2014;94(4):1077-1098. doi:10.1152/ physrev.00041.2013

21. Gaude E, Nougueira B, Smith S, et al. A novel combination of blood biomarkers clinical stroke scale facilitates detection of large vessel occlusion ischemic strokes. Diagnostics (Basel). 2021;11(7):1137. doi:10.1101/2021.01.06.21249344

22. Liu G, Geng J. Glial fibrillary acidic protein as prognostic biomarker of acute ischemic stroke. Hum Exp Toxicol. 2018;37(10):1048-1053. doi:10.1177/0960327117751236
Journal of Inflammation Research

\section{Publish your work in this journal}

The Journal of Inflammation Research is an international, peerreviewed open-access journal that welcomes laboratory and clinical findings on the molecular basis, cell biology and pharmacology of inflammation including original research, reviews, symposium reports, hypothesis formation and commentaries on: acute/chronic inflammation; mediators of inflammation; cellular processes; molecular mechanisms; pharmacology and novel anti-inflammatory drugs; clinical conditions involving inflammation. The manuscript management system is completely online and includes a very quick and fair peerreview system. Visit http://www.dovepress.com/testimonials.php to read real quotes from published authors. 